See Article page 1407.

\section{Commentary: Is angiotensin II a game changer for vasoplegia after cardiac surgery, or is the jury still out?}

\section{Subhasis Chatterjee, MD}

Few clinical conundrums are as frustrating and distressing as completing a technically challenging double valve replacement for endocarditis, a complex reoperative aortic reconstruction, or heart transplantation, only to encounter profound vasoplegic shock. Despite maximal use of vasoactive medications and even "hail Mary" rescue strategies such as methylene blue and glucocorticoids, achieving acceptable blood pressure still might not be possible. Enter angiotensin II (Ang-II), a medication that has been around since the 1960s and that might help address this conundrum. In this issue of the Journal, Chow and a multicenter group of experienced colleagues ${ }^{1}$ provide an expert opinion piece addressing the role of Ang-II in treating vasoplegia after cardiac surgery. The authors have offered a comprehensive summary with a mix of biochemical laboratory evidence and real-world clinical outcomes that will be valuable for surgeons, anesthesiologists, intensivists, and others involved in the perioperative care of patients with postcardiotomy vasoplegia.

Vasoplegic shock is hypotension (mean arterial pressure $<60-65 \mathrm{~mm} \mathrm{Hg}$ ) that is refractory to vasopressor therapy and characterized by high cardiac output (cardiac index $>2.2-2.5 \mathrm{~L} / \mathrm{min} / \mathrm{m}^{2}$ ) and low systemic vascular resistance $\left(<800\right.$ dynes $\left./ \mathrm{sec} / \mathrm{cm}^{-5}\right)$. A limitation in the current literature is the lack of a consensus definition of vasoplegia, which may explain the variability in its reported incidence and outcomes. Regardless, vasoplegic shock is consistently

From the Divisions of General Surgery and Cardiothoracic Surgery, Michael E. DeBakey Department of Surgery, Baylor College of Medicine and Department of Cardiovascular Surgery, Texas Heart Institute, Houston, Tex.

Disclosures: The author has served on the advisory boards of La Jolla Pharmaceuticals and Edwards Lifesciences.

The Journal policy requires editors and reviewers to disclose conflicts of interest and to decline handling or reviewing manuscripts for which they may have a conflict of interest. The editors and reviewers of this article have no conflicts of interest.

Received for publication March 19, 2021; revisions received March 19, 2021; accepted for publication March 23, 2021; available ahead of print March 26, 2021.

Address for reprints: Subhasis Chatterjee, MD, Baylor College of Medicine, One Baylor Plaza, MS: BCM 390, Houston, TX 77030-3411 (E-mail: subhasis. chatterjee@bcm.edu).

J Thorac Cardiovasc Surg 2022;163:1415-6

$0022-5223 / \$ 36.00$

Copyright (c) 2021 by The American Association for Thoracic Surgery

https://doi.org/10.1016/j.jtcvs.2021.03.074

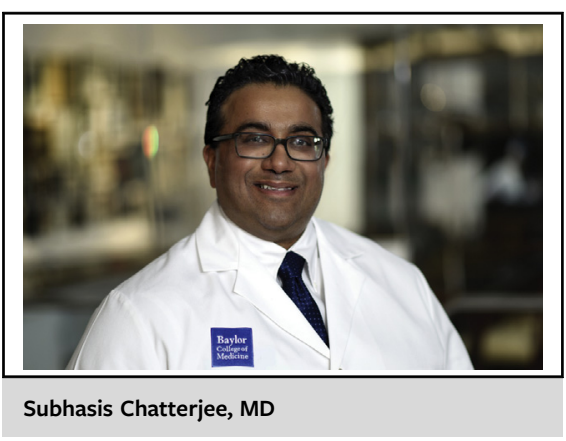

CENTRAL MESSAGE

Vasoplegic shock after cardiac surgery is associated with substantial mortality, and few therapeutic agents exist. Angiotensin II is promising for restoring normotension; clinical trials are needed.

associated with high mortality $(15 \%-30 \%)$ after cardiac surgery. Indeed, the relative paucity of high-quality studies in this field is underscored by a recent consensus statement whose major (but limited) conclusions (use norepinephrine or vasopressin, avoid dopamine) were based on moderatequality evidence at best. ${ }^{2}$

Ever more studies are investigating the use of Ang-II in various contexts after cardiac surgery ${ }^{3}$ and even thoracoabdominal aortic aneurysm repair. ${ }^{4}$ In the landmark Angiotensin II for the Treatment of High-Output Shock (ATHOS-3) trial, patients were randomized to Ang-II or standard of care vasopressors; the primary endpoint was a mean arterial pressure $>75 \mathrm{~mm} \mathrm{Hg}$ within 3 hours. This study, mostly in patients with sepsis $(80 \%)$, raised a few important questions that the authors' review of the published literature explains well..$^{5}$ Specifically, given that approximately $30 \%$ of the patients overall were nonresponders to Ang-II, how would a cardiac surgery cohort fare? Although relatively few patients in the ATHOS-3 trial had undergone cardiac surgery $(4.7 \% ; 16$ of 344$)$, this was examined in detail in a post hoc analysis. ${ }^{6}$ In that report, $89 \%$ of the cardiac surgery cohort reached the target mean arterial pressure. In addition, the overall ATHOS-3 Ang-II cohort had a higher rate of venous thromboembolism (VTE) than the standard of care group $(13 \%$ vs $5 \%)$ but a similar rate of clinically significant VTEs (2\% vs $0 \%)$. In contrast, other published Ang-II 
reports in cardiac surgery patients did not show different VTE rates. ${ }^{1}$ This is critical, as physicians may hesitate to initiate Ang-II, especially in situations involving mechanical circulatory support or prosthetic valvesalthough the concomitant use of systemic anticoagulation mitigates potential risk.

It is well known that longer cardiopulmonary bypass time is consistently associated with the development of vasoplegia. ${ }^{3}$ One possible pathophysiological explanation for this is the increased endothelial pulmonary dysfunction owing to activation of inflammatory markers and the development of vasoplegic shock. A unique contribution that Chow and colleagues highlight is the concept of using "high renin shock" to better characterize vasoplegia, which has been associated with increased mortality in patients treated with standard care instead of Ang-II. ${ }^{7}$ It is notable that high renin levels are indicative of deficiencies in the renin-angiotensin-aldosterone system (RAAS). This may be an avenue for identifying patients most likely to benefit from Ang-II administration. Indeed, earlier suggestions to avoid vasoplegia and stop RAAS inhibitors before cardiac surgery prompted van Diepen and colleagues $^{8}$ to randomize 121 patients either to discontinuation of RAAS inhibitors 2 days before cardiac surgery or to no discontinuation. No differences were found in the frequency of postoperative vasoplegic shock, intravenous vasopressor use, duration of use, mortality, or morbidity. Perhaps the lower-risk patients were not those who could most benefit from discontinuation; further identification of a higher-risk group by using renin measurements may lead to better-targeted interventions.

The Vasopressin versus Norepinephrine in Patients with Vasoplegic Shock after Cardiac Surgery (VANCS) study $^{9}$ is the only dedicated randomized trial evaluating vasopressor therapy in an exclusively cardiac surgery setting. In this Brazilian trial, 300 patients were randomized to monotherapy with either norepinephrine or vasopressin; a major reduction in acute kidney injury and postoperative atrial fibrillation was seen in the vasopressin group. Postcardiotomy atrial fibrillation may have unique relevance as an endpoint in future Ang-II studies.

The authors are to be commended for highlighting the concept of norepinephrine equivalents for those less familiar with that concept. We need to speak a common language to be able to make appropriate comparisons. This is a much more meaningful distinction than simple comparisons of whether a patient is on one versus two vasopressors, as one high-dose vasopressor may signal more extensive vasoplegia than two lower-dose vasopressors.
A cost-benefit analysis is the first task for any pharmacy and therapeutics committee deciding whether to accept Ang-II into the formulary. At our own hospital, in a 100$\mathrm{kg}$ man, the cost for 24 hours of treatment is $\$ 30$ for norepinephrine, $\$ 400$ for vasopressin, and $\$ 1400$ for Ang-II. The concept of "last on, first off" readily applies to Ang-II in this regard. Nonetheless, the authors highlight the overall favorable economic outcomes with Ang-II. In addition, methylene blue is approximately $\$ 100$ per dose, compared with $\$ 1200$ for hydroxocobalamin, so the alternatives can be costly as well. Further cost-benefit analysis that focuses on intensive care unit length of stay and need for renal replacement therapy may provide additional insight on the economic impact of Ang-II.

The authors correctly conclude that quality, robust clinical trials addressing postcardiotomy vasoplegic shock are needed to help define the role of Ang-II. There is still too much practice by anecdotal experience, too little highquality data, and inconsistent escalation algorithms in vasoplegia. After all, if $10 \%$ of the half-million patients who undergo cardiac surgery each year develop vasoplegia, the opportunity to meaningfully influence practice is substantial. Angiotensin II may not be a game changer in all cases of vasoplegia, and the jury is still out on whether Ang-II confers clinical benefit-but initial results warrant cautious optimism.

\section{References}

1. Chow JH, Wittwer ED, Wieruszewski PM, Khanna AK. Evaluating the evidence for angiotensin II for the treatment for vasoplegia in critically ill cardiothoracic surgery patients. J Thorac Cardiovasc Surg. 2022;163:1407-14.

2. Guarracino F, Habicher M, Treskatsch S, Sander M, Szekely A, Paternoster G, et al. Vasopressor therapy in cardiac surgery - an experts' consensus statement. J Cardiothorac Vasc Anesth. 2021;35:1018-29.

3. Dayan V, Cal R, Giangrossi F. Risk factors for vasoplegia after cardiac surgery: a meta-analysis. Interact Cardiovasc Thorac Surg. 2019;28:838-44.

4. Chatterjee S, Preventza O, Mousavi MC, Orozco-Sevilla V, LeMaire SA, Coselli JS. Successful use of angiotensin II for vasoplegia after thoracoabdominal aortic aneurysm repair. J Thorac Cardiovasc Surg Tech. 2020;4:72-5.

5. Khanna A, English SW, Wang XS, Ham K, Tumlin J, Szerlip H, et al. Angiotensin II for the treatment of vasodilatory shock. N Engl J Med. 2017;377:419-30.

6. Klijian A, Khanna AK, Reddy VS, Friedman B, Ortoleva J, Evans AS, et al. Treatment with angiotensin II is associated with rapid blood pressure response and vasopressor sparing in patients with vasoplegia after cardiac surgery: a post-hoc analysis of Angiotensin II for the Treatment of High-Output Shock (ATHOS-3) study. J Cardiothorac Vasc Anesth. 2021;35:51-8.

7. Bellomo R, Forni LG, Busse LW, McCurdy MT, Ham KR, Boldt DW, et al. Renin and survival in patients given angiotensin II for catecholamine-resistant vasodilatory shock. A clinical trial. Am J Respir Crit Care Med. 2020;202:1253-61.

8. van Diepen S, Norris CM, Zheng Y, Nagendran J, Graham MM, Gaete Ortega D, et al. Comparison of angiotensin-converting enzyme inhibitor and angiotensin receptor blocker management strategies before cardiac surgery: a pilot randomized controlled registry trial. J Am Heart Assoc. 2018;7:e009917.

9. Hajjar LA, Vincent JL, Barbosa Gomes Galas FR, Rhodes A, Landoni G, Osawa EA, et al. Vasopressin versus norepinephrine in patients with vasoplegic shock after cardiac surgery: the VANCS randomized controlled trial. Anesthesiology. 2017;126:85-93. 